\title{
The effect of sociodemographic and clinical features on mortality in patients with diagnosis of aspiration pneumonia
}

\author{
Mehmet Nuri Ozer ${ }^{1}$, Mehmet Uzunlulu' ${ }^{1}$, Aytekin Oguz ${ }^{1}$, Osman Kostek ${ }^{1}$, \\ Erdal Akyer ${ }^{1}$, Mumtaz Takir ${ }^{2}$ \\ 1Department of Internal Medicine, Istanbul Medeniyet University Goztepe Training and Research Hospital, Istanbul, Turkey \\ ${ }^{2}$ Department of Internal Medicine and Division of Endocrinology, Istanbul Medeniyet University Goztepe Training and Research \\ Hospital, Istanbul, Turkey
}

\begin{abstract}
OBJECTIVE: The aim of this study was to evaluate the sociodemographic and clinical chracteristics of patients hospitalized with aspiration pneumonia in internal medicine clinics, and to determine the incidence and parameters of mortality among these patients.
\end{abstract}

METHODS: Patients over the age of 18 years who were hospitalized in clinics of internal medicine between Janu-

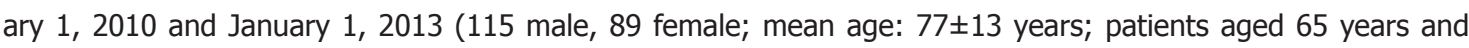
over, $88.2 \%$; average duration of hospitalization, $11 \pm 9$ days) were evaluated retrospectively and consecutively. The incidence of mortality, nutritional status at admission, comorbidity frequency, haematological and biochemical data and their relationship with mortality were evaluated.

RESULTS: At admission, $85 \%$ of the patients were fed through oral route, while $15 \%$ of them were fed through PEG. There was no relation between nutritional status of the patients (oral, nasogastric tube or PEG) at admission, and development of aspiration pneumonia. Commonly seen comorbidities were dementia (49\%), hypertension (43\%), cerebrovascular accident (42\%), and diabetes mellitus (31\%) respectively. The mortality rate was $24.5 \%$ (in first three days, $56 \%$ ). A correlation was found between mortality and increase in neutrophil/lymphocyte ratio (NLR) and increased uric acid rate (for both $p<0.05$ ).

CONCLUSION: In this study, the mortality rates among patients diagnosed with aspiration pneumonia was found to be increased. The high number of geriatric patients and comorbidities might have played a role in this situation. Neutrophil/lymphocyte ratio (NLR) and uric acid levels in patients with aspiration pneumonia might be evaluated as factors related to mortality.

Key words: Aspiration pneumonia; comorbidity; internal medicine clinic; mortality.

Received: January 30, 2015 Accepted: April 09, 2015 Online: April 24, 2015

Correspondence: Dr. Mehmet NURI OZER. Goztepe Egitim ve Arastirma Hastanesi, Ic Hastaliklari Klinigi, 34710 Istanbul, Turkey.

Tel: +90 216 - 5709195 e-mail: drnuri21@hotmail.com

(c) Copyright 2015 by Istanbul Northern Anatolian Association of Public Hospitals - Available online at www.kuzeyklinikleri.com 
A spiration pneumonia is an alveolar infection stemming from inhalation of the pathogenic material in the oropharynx [1]. Demographic factors as advanced age, male gender, comorbidities as dysphagia, diabetes mellitus, severe dementia, deletion of angiotensin - converting enzyme-1, genotype, bad oral hygiene, Parkinson's disease, malnutrition medications as antipsychotics, proton pump inhibitors, and ACE-inhibitors have been demonstrated as risk factors for aspiration pneumonia [2].

Aspiration pneumonia constitutes $5-15 \%$ of community-acquired pneumonia, and it is still responsible for $20 \%$ of community-acquired pneumonia among elder people, and ranks second among the most frequently seen nosocomial infections after urinary tract infections $[1,3,4]$. Actural incidence of aspiration pneumonia may be higher. As observed by many authors, indeed $50 \%$ of healthy individuals, and $70 \%$ of the elder population have aspirated something during their sleep $[5,6]$. Aspiration pneumonia is one of the most important causes of hospitalization especially of elder people, those with neurological problems or individuals staying in nursing homes.

In the community, the number of geriatric patients increase in parallel with prolongation of mean life span. In addition, higher incidence of comorbidities as dementia, stroke, Alzheimer's disease, diabetes, and hypertension also increases rates of hospitalization. The objective of this study was to evaluate mortality, nutritional status, sociodemographic characteristics, and factors effective on martality.

\section{MATERIALS AND METHODS}

Medical files of the patients aged 18 and over who were hospitalized in the Clinics of Internal Medicine of Istanbul Medeniyet University Goztepe Training and Research Hospital between January 1, 2010, and January 1, 2013 with the diagnosis of pneumonia were retrieved from otomation system, and patients' archives of the hospital and analyzed, and included in the study. The approval (date: January 24, 2013; decision \# $\$ 30 / \mathrm{H}$ ) of the Ethics Committee of Istanbul Medeniyet University Goztepe Training and Research Hospital was obtained.
During the study period, principles of Helsinki Declaration were taken into consideration.

Study design: On patient registration forms, age, gender, diagnosis of admission in the Service of Internal Medicine, nutritional status, duration of hospitalization, clinical, and laboratory information, and prognoses (rates of discharge or exitus), comorbidities (chronic obstructive pulmonary disease, diabetes mellitus, heart failure, hypertension, chronic renal disease, chronic ischemic heart disease, atrial fibrillation, dementia, Parkinson's disease, and cerebrovascular disease) were recorded. Mortality rates, nutritional status, frequency of comorbidities, hematological, and biochemical data, and their relation with mortality were evaluated. Data of the patients discharged, and exited were also compared.

Diagnosis of aspiration pneumonia: Despite lack of defined, and precise diagnostic criteria diagnosis of aspiration pneumonia was made based on witnessed event of aspiration or strong evidence of suspect aspiration (abnormal swallowing function, and dysphagia) and confirmation of findings of pulmonary inflammation [1].

Laboratory parametres: From patients'files, whole blood counts, biochemical data (glucose, urea, uric acid, creatinine, sodium, potassium, phosphorus, aspartate aminotransferase, alanine transferase, total bilirubin, indirect bilirubin, gamma glutamyl transferase, alkaline transferase, lactate dehydrogenase, cholesterol, triglyceride, HDL-cholesterol, LDL-cholesterol, creatinine kinase, CK-MB, iron, iron-binding capacity, amilase, lipase, protein, albumin, sedimentation rate, C-reactive protein, aPTT, INR, HbA1c, TSH, freeT3, free T4, ferritin, folic acid, and vitamin B12) were recorded.

Statistical analyses were performed using SPSS for Windows V.21.0 program. Before analyses, fitness of variables to normal distribution pattern was analyzed using Kolmogorov- Smirnov test. Continuous variables were expressed as mean $\pm \mathrm{SD}$. Classified and numerical data were analyzed using chi-square test, Student's t test, and Mann-Whitney $U$ test, respectively. Independent factors effective on mortality, and results of logistic regression analysis were expressed as levels of significance, and 
estimated relative risks (odds ratio-OR), and 95\% confidence intervals (95\% CI) Results at a level of significance of $p<0.05$ within $95 \%$ confidence interval were accepted as statistically significant values.

\section{RESULTS}

A total of 204 (115 male, and 89 female) patients diagnosed as aspiration pneumonia with a mean age of $77 \pm 13$ years, and duration of hospitalization of $11 \pm 9$ days were included in the study. Median mortality rate was 24.5 percent. Eighty-eight percent of the patients were older than 65 years of age. Nearly $56 \%$ of the deaths occurred within the first 3 days. At first admission, the patients were receiving their nutrients through oral route $(\mathrm{n}=174 ; 85 \%)$ or percutaneous endoscopic gastrostomy (PEG) $(\mathrm{n}=30 ; 15 \%)$. Distribution of demographic data, and comorbidities are given in Table 1 . The most frequently associated comorbidities were dementia (49\%), hypertension (43\%), cerebrovascular events $(42 \%)$, and diabetes mellitus (31\%). Hospitalization rates were higher in discharged patients when compared with exited patients $(\mathrm{p}=001)$.

Laboratory data are given in Tables 2 , and 3.
When compared with survived patients, in exited patients neutrophil/lymphocyte ratio, urea, uric acid, ALP, LDH, phosphorus, prothrombin time were relatively higher (for all, $\mathrm{p}<0.05$ ), while TSH, and free T3 levels were lower (for all, $\mathrm{p}<0.05$ ).

In a multivariate logistic regression analysis where factors effective on mortality were evaluated, increased uric acid levels, and neutrophil/lymphocyte ratios predicted mortality. In these patients uric acid levels, and neutrophil/lymphocyte ratios were higher in exited patients when compared with those discharged. Uric acid levels higher than $5.35 \mathrm{mg} /$ $\mathrm{dL}(\mathrm{AUC}=0.620)$ have $61.3 \%$ sensitivity, and $62 \%$ specificity in predicting mortality, however neutrophil/lymphocyte ratios over 10.63 (AUC=0.608) have $44 \%$ sensitivity, and $74 \%$ specificity in predicting mortality.

\section{DISCUSSION}

In this study, $88.2 \%$ of the cases with aspiration pneumonia were over 65 years of age, and at admission the patients were fed via oral $(85 \%)$ route or PEG (15\%). Development of aspiration pneumonia had no effect on the patients' nutritional

TABLE1. Demographic characteristics and comorbidities of the patients

\begin{tabular}{|c|c|c|c|c|c|c|c|}
\hline & \multicolumn{2}{|c|}{$\begin{array}{c}\text { Total } \\
(n=204)\end{array}$} & \multicolumn{2}{|c|}{$\begin{array}{l}\text { Discharged } \\
(n=154)\end{array}$} & \multicolumn{2}{|c|}{$\begin{array}{l}\text { Exited } \\
(n=50)\end{array}$} & \multirow[t]{2}{*}{$\mathrm{p}$} \\
\hline & $\mathrm{n}$ & $\%$ & $\mathrm{n}$ & $\%$ & $\mathrm{n}$ & $\%$ & \\
\hline Age, years & \multicolumn{2}{|c|}{$77 \pm 13$} & \multicolumn{2}{|c|}{$78 \pm 13$} & \multicolumn{2}{|c|}{$75 \pm 16$} & NS \\
\hline Gender, M/F & \multicolumn{2}{|c|}{$115 / 89$} & \multicolumn{2}{|l|}{$89 / 65$} & \multicolumn{2}{|l|}{$26 / 24$} & NS \\
\hline Duration of hospitalization, days & \multirow{2}{*}{\multicolumn{2}{|c|}{$11 \pm 9$}} & \multirow{2}{*}{\multicolumn{2}{|c|}{$12 \pm 7$}} & \multirow{2}{*}{\multicolumn{2}{|c|}{$7 \pm 12$}} & 0.001 \\
\hline Comorbidities & & & & & & & \\
\hline Renal diseases & 14 & 6.6 & 8 & 4 & 6 & 3 & NS \\
\hline Diabetes mellitus & 64 & 31 & 42 & 21 & 32 & 15 & NS \\
\hline Hypertension & 91 & 45 & 65 & 33 & 26 & 13 & NS \\
\hline Congestive heart failure & 27 & 13 & 19 & 9 & 18 & 5 & NS \\
\hline Atrial fibrillatiion & 26 & 12 & 14 & 7 & 12 & 6 & NS \\
\hline Chronic ischemic heart disease & 34 & 17 & 24 & 12 & 10 & 5 & NS \\
\hline Dementia & 104 & 49 & 83 & 42 & 21 & 11 & NS \\
\hline Parkinsonism & 20 & 10 & 18 & 9 & 2 & 1 & NS \\
\hline Cerebrovascular disease & 89 & 42 & 69 & 35 & 20 & 10 & NS \\
\hline
\end{tabular}


TABLE2. Hematological parameters of patients with aspiration pneumonia

\begin{tabular}{lcccc} 
& $\begin{array}{c}\text { Total } \\
(\mathrm{n}=204)\end{array}$ & $\begin{array}{c}\text { Discharged } \\
(\mathrm{n}=154)\end{array}$ & $\begin{array}{c}\text { Exited } \\
(\mathrm{n}=50)\end{array}$ & $\mathrm{p}$ \\
\hline Hematocrit $(\%)$ & $34.5 \pm 7.5$ & $34.7 \pm 8.1$ & $33.8 \pm 5.5$ & $\mathrm{NS}$ \\
Platelet $\left(10^{3} / \mathrm{mm}^{3}\right)$ & $284 \pm 140$ & $292 \pm 142$ & $258 \pm 126$ & NS \\
Leukocyte $\left(10^{3} / \mathrm{mm}^{3}\right)$ & $13447 \pm 6180$ & $13200 \pm 6150$ & $14200 \pm 6275$ & NS \\
Neutrophil $\left(10^{3} / \mathrm{mm}^{3}\right)$ & $11380 \pm 7670$ & $11196 \pm 8160$ & $11950 \pm 5960$ & NS \\
Lymphocyte $\left(10^{3} / \mathrm{mm}^{3}\right)$ & $1300(900-1800)$ & $1300(900-1800)$ & $800(700-1400)$ & 0.02 \\
Neutrophil/Lymphocyte & $7.6(4.3-12.3)$ & $7.1(3.8-11.4)$ & $8.7(4.5-19.7)$ & 0.05 \\
Neutrophil/Leukocyte & $0.82(0.74-0.88)$ & $0.82(0.75-0.87)$ & $0.82(0.76-0.91)$ & NS \\
Lymphocyte/Leukocyte & $0.13 \pm 0.08$ & $0.13 \pm 0.058$ & $0.11 \pm 0.08$ & NS \\
MCV ${ }^{1}(\mathrm{fL})$ & $88(84-94)$ & $88(84-93)$ & $84(82-95)$ & NS \\
RDW ${ }^{2}(\%)$ & $15.5 \pm 2.5$ & $15.3 \pm 2.2$ & $15.7 \pm 3.1$ & NS \\
MPV 3 (fL) & $9.8 \pm 6.9$ & $9.9 \pm 7.9$ & $9.4 \pm 1.3$ & NS \\
PDW ${ }^{4}(\mathrm{GSD})$ & $16.3(15.6-17.5)$ & $16.3(15.6-17.5)$ & $16.3(15.8-17.5)$ & NS \\
Iron $(\mu \mathrm{gr} / \mathrm{dL})$ & $23(14-37)$ & $23(14-35)$ & $40(18-48)$ & NS \\
Folate $(\mathrm{pg} / \mathrm{ml})$ & $8.1 \pm 5.5$ & $8.1 \pm 5.6$ & $7.9 \pm 5.2$ & NS \\
Vitamin B12 $(\mathrm{pg} / \mathrm{ml})$ & $320(198-520)$ & $316(198-542)$ & $542(270-970)$ & 0.05 \\
\hline
\end{tabular}

MCV1: Mean corpuscular volume; RDW²: Erythrocyte distribution width (\%); MPV3: Mean platelet volume; PDW4: Platelet distribution width.

status (oral, nasogastric tube or PEG). The most frequently seen comorbidities were dementia, hypertension, cerebrovascular event, and diabetes mellitus. Mortality rate was $24.5 \%$ (56\% within the first 3 days). Increase in neutrophil/lymphocyte ratios (NLRs), and uric acid levels were found to be related to mortality (for both, $\mathrm{p}<0.05$ ).

Demographic characteristics as advanced age, and male gender were known to be risk factors for aspiration pneumonia. In a study where mortality rates in inpatients with aspiration pneumonia were investigated, median age of the patients, and percentage of male patients were reported as 76.7 years, and $50.2 \%$, respectively [7]. In a prospective study on 62 cases performed by Tokuyasu et al. median age of the patients was 86.6 years, and male patients constituted $56.8 \%$ of the study population [8]. In their retrospective study by Fidan et al. on 31 cases with aspiration pneumonia, median age of their study population was 61 years, while $55 \%$ of their patients consisted of male patients [9]. In our study median age of 204 patients diagnosed as aspiration pneumonia in the clinics of internal medi- cine was 77 years, and $56 \%$ of the study population comprised of male patients. Similar to the literature findings, distribution of aspiration pneumonia was nearly the same in both genders, and medain age of the patients was similar to that encountered during literature reviews.

Aspiration can cause serious problems especially in patients with dementia. In a study by Feinberg et al. the authors performed a study in nursing home patients using modified videofluoroscopy guided swallowing test with barium, and detected events of major, and minor aspiration in 24 , and $50 \%$ of the patients, respectively [10]. In a study by Metan et al. the most frequent comorbidity in their patients with aspiration pneumonia was neurological diseases $(78 \%)$ which were detected in $20 \%$ of the patients with dementia [11]. Still in our study, great majority of the patients with aspiration pneumonia had a neurological disease (cerebrovascular disease, dementia, Parkinson's disease), and $49 \%$ of the study population consisted of patients with dementia.

Relationship between enteral nutrition, and complication of aspiration is already acknowledged. 
TABLE 3. Biochemical parameters of the patients

\begin{tabular}{|c|c|c|c|c|}
\hline & $\begin{array}{c}\text { Total } \\
(n=204)\end{array}$ & $\begin{array}{l}\text { Exited } \\
(n=50)\end{array}$ & $\begin{array}{c}\text { Discharged } \\
(n=154)\end{array}$ & $\mathrm{p}$ \\
\hline Glucose (mg/dL) & $109(82-162)$ & $149(85-178)$ & $108(82-145)$ & 0.02 \\
\hline Urea $(\mathrm{mg} / \mathrm{dL})$ & $61(41-113)$ & $79(46-156)$ & $56(38-101)$ & 0.002 \\
\hline Uric acid $(\mathrm{mg} / \mathrm{dL})$ & $5(3.5-6.5)$ & $5.9(4.1-8.2)$ & $4.9(3.4-5.9)$ & 0.003 \\
\hline Creatinine (mg/dL) & $0.9(0.6-1.4)$ & $1.3(0.7-2.6)$ & $0.9(0.6-1.2)$ & 0.015 \\
\hline Sodium (mEq/L) (Mean \pm SD) & $141 \pm 10$ & $140 \pm 10$ & $141 \pm 10$ & NS \\
\hline Potassium (mEq/L) (Mean \pm SD) & $4.2(3.7-4.5)$ & $4.3(3.9-4.9)$ & $4.1(3.6-4.4)$ & NS \\
\hline $\operatorname{AST}^{1}(\mathrm{U} / \mathrm{L})$ & $26(18-49)$ & $30(22-69)$ & $25(18-42)$ & 0.02 \\
\hline $\operatorname{ALT}^{2}(U / L)$ & $20(13-35)$ & $25(13-41)$ & $20(13-32)$ & 0.04 \\
\hline T bilirubin ${ }^{3}$ (mg/dL) & $0.56(0.37-0.8)$ & $0.64(0.47-0.89)$ & $0.53(0.36-0.88)$ & 0.02 \\
\hline I Bilirubin 4 (mg/dL) & $0.41(0.28-0.6)$ & $0.45(0.23-0.65)$ & $0.41(0.27-0.62)$ & 0.05 \\
\hline $\mathrm{GGT}^{5}(\mathrm{U} / \mathrm{L})$ & $29(16-62)$ & $48(16-98)$ & $27(17-53)$ & 0.01 \\
\hline $\operatorname{ALP}^{6}(U / L)$ & $79(64-100)$ & $92(73-114)$ & $76(61-93)$ & 0.003 \\
\hline $\mathrm{LDH}^{7}(\mathrm{U} / \mathrm{L})$ & $244(211-329)$ & $262(227-367)$ & $246(207-288)$ & 0.007 \\
\hline Cholesterol $(\mathrm{mg} / \mathrm{dL})($ Mean $\pm \mathrm{SD})$ & $136 \pm 45$ & $142 \pm 64$ & $134 \pm 39$ & NS \\
\hline Triglyceride $(\mathrm{mg} / \mathrm{dL})($ Mean $\pm \mathrm{SD})$ & $115 \pm 70$ & $129 \pm 65$ & $111 \pm 73$ & NS \\
\hline $\mathrm{HDL}-\mathrm{C}^{8}(\mathrm{mg} / \mathrm{dL})($ Mean $\pm \mathrm{SD})$ & $33 \pm 15$ & $32 \pm 18$ & $33 \pm 14$ & NS \\
\hline LDL-C ${ }^{9}(\mathrm{mg} / \mathrm{dL})($ Mean $\pm \mathrm{SD})$ & $83 \pm 37$ & $85 \pm 49$ & $82 \pm 33$ & NS \\
\hline $\mathrm{CK}^{10}(\mathrm{U} / \mathrm{L})$ & $106(47-224)$ & $77(29-109)$ & $122(52-227)$ & NS \\
\hline Protein $(\mathrm{g} / \mathrm{dL})($ Mean $\pm \mathrm{SD})$ & $6.1 \pm 0.8$ & $6.1 \pm 0.7$ & $6.2 \pm 0.8$ & NS \\
\hline $\operatorname{HbA1c}^{11}(\%)$ & $5.8(5.5-6.7)$ & $5.8(5.6-7)$ & $5.7(5.5-6.6)$ & NS \\
\hline Phosphorus (mEq/L) & $3.3(2.8-4)$ & $4(3.2-4.7)$ & $3.2(2.7-3.7)$ & $<0.001$ \\
\hline $\operatorname{INR}^{12}(\%)$ & $1.25(1.18-1.36)$ & $1.32(1.25-1.45)$ & $1.23(1.16-1.3)$ & 0.008 \\
\hline $\mathrm{TSH}^{13}(\mathrm{uIU} / \mathrm{mL})$ & $1.12(0.66-2.26)$ & $0.99(0.33-1.91)$ & $1.33(0.69-2.34)$ & 0.059 \\
\hline FreeT3 ${ }^{14}(\mathrm{pgr} / \mathrm{mL})$ & $2.06(1.74-2.30)$ & $1.85(1.59-2.15)$ & $2.12(1.81-2.33)$ & 0.005 \\
\hline FreeT4$^{15}(\mathrm{ng} / \mathrm{dL})$ & $1.06(0.87-1.23)$ & $1.08(0.89-1.23)$ & $1.06(0.87-1.23)$ & NS \\
\hline
\end{tabular}

AST$^{1}$ : Acid transferase; ALT²: Alkaline transferase; T. bilirubin ${ }^{3}$ : Total bilirubin; I. Bilirubin: Indirect bilirubin; GGT5: Gamma glutamyl transferase; ALP6: Alkaline phosphatase; $\mathrm{LDH}^{7}$ : Lactate dehydrogenase; HDL-C $\mathrm{C}^{8}$ : High-density lipoprotein cholesterol; LDL-C9: Low-density lipoprotein cholesterol; $\mathrm{CK}^{10}$ : Creatinine kinase; HbA1c ${ }^{11}$ : Hemoglobin A1c; INR ${ }^{12}$ : International normalized ratio; TSH $^{13}$ : Thyroid stimulating hormone; Free T3 ${ }^{14}$ : Triiodothyronine; FreeT4 ${ }^{15}$ : Thyroxine.

In patients on tube feeding, and those dependent on others for oral hygiene, the risk of aspiration was observedly 20-fold higher when compared with healthy individuals $[12,13]$. Nakajoh et al. investigated one-year incidence of aspiration pneumonia in patients who experienced a cerebrovascular event, and observed its incidence as $54.3 \%$ in dysphagic patients on oral intake which was higher than dysphagic cases on tube feeding (13.2\%). The incidence of aspiration pneumonia was $64.3 \%$ in bedridden patients fed through nasogastric tube [14]. Our patients were fed via PEG (15\%) or through oral route $(85 \%)$ at admission. This finding suggests that aspiration pneumonia is more frequently seen in elder patients fed through oral route, and alimentation through PEG has not any prophylactic effect in these cases.

Though mortality rates of aspiration pneumonia ranged between 20 , and $50 \%$, in some studies higher rates up to $80 \%$ have been reported $[15,16,17,18]$. In our study median rate of mortality was found as $24.5 \%$ in compliance with the literature findings. In cases with aspiration pneumonia, disparities between mortality rates can be attributed to the lack 
of definitive diagnostic criteria defined for aspiration pneumonia, and higher mortality rates can be associated with advanced age of these patients, and concomitant diseases.

In recent years an index which reflects both acute inflammation, and lymphopenia developing after acute physiologic stress has been started to be used. This index is a neutrophil/lymphocyte ratio which has been reported to be a good marker of the inflammatory state [19]. Duffy et al. divided 1046 patients into 3 groups (mean NLR 1.7 \pm 0.5 ; $3.2 \pm 0.6 ; 11.2 \pm 12.9$ ) before percutaneous coronary intervention, and followed them for postoperative 32 months. They reported 144 cases of death, and in patients with increased neutrophil/lymphocyte ratios, higher mortality rates were detected [20]. In a study performed on non-small cell lung cancer patients who had undergone complete resection, Sarraf et al. detected higher mortality rates in patients with increased neutrophil/lymphocyte ratios [21]. Uthamalingam et al. divided 1212 patients with diagnosis of acute decompensated heart disease according to their neutrophil/lymphocyte ratios, and found a positive correlation between mortality, and neutrophil/lymphocyte ratios during a median follow-up period of 26 months [22]. In our study, we also found a correlation between mortality, and neutrophil/leukocyte ratios in patients with aspiration pneumonia which suggests that this parametre can be used as an easily available, simple, and cost-effective marker.

Uric acid is considered as a cardiovascular risk marker [23]. In a study performed by Tomita et al. the authors reported higher risk of all-cause death (from coronary heart disease, stroke, liver disease and/or renal failure) in 49413 patients aged between 25, and 60 years with uric acid levels over $8.5 \mathrm{mg} / \mathrm{dl}$ during a median follow-up period of 5.5 years when compared with those with uric acid levels at 5-6.4 mg/dl [24]. In our study relationship between uric acid levels, and mortality supports their outcome.

In conclusion, in this study we found increased mortality rates in patients hospitalized with the diagnosis of aspiration pneumonia. Higher number of geriatric patients, and also higher incidence rates of comorbidities may be responsible for higher mor- tality rates. Neutrophil/lymphocyte ratios (NLR), and uric acid levels can be evaluated as mortalityrelated factors in cases with aspiration pneumonia.

Conflict of Interest: No conflict of interest was declared by the authors.

Financial Disclosure: The authors declared that this study has received no financial support.

\section{REFERENCES}

1. Marik PE. Aspiration pneumonitis and aspiration pneumonia. N Engl J Med 2001;344:665-71. CrossRef

2. van der Maarel-Wierink CD, Vanobbergen JN, Bronkhorst EM, Schols JM, de Baat C. Risk factors for aspiration pneumonia in frail older people: a systematic literature review. J Am Med Dir Assoc 2011;12:344-54. CrossRef

3. Mylotte JM. Nursing home-acquired pneumonia. Clin Infect Dis 2002;35:1205-11. CrossRef

4. Langmore SE, Terpenning MS, Schork A, Chen Y, Murray JT, Lopatin D, et al. Predictors of aspiration pneumonia: how important is dysphagia? Dysphagia 1998;13:69-81. CrossRef

5. Marrie TJ. Community-acquired pneumonia in the elderly. Clin Infect Dis 2000;31:1066-78. CrossRef

6. Gleeson K, Eggli DF, Maxwell SL. Quantitative aspiration during sleep in normal subjects. Chest 1997;111:1266-72. CrossRef

7. Heppner HJ, Sehlhoff B, Niklaus D, Pientka L, Thiem U. Pneumonia Severity Index (PSI), CURB-65, and mortality in hospitalized elderly patients with aspiration pneumonia. [Article in German] Z Gerontol Geriatr 2011;44:229-34. [Abstract] CrossRef

8. Tokuyasu H, Harada T, Watanabe E, Okazaki R, Touge H, Kawasaki Y, et al. Effectiveness of meropenem for the treatment of aspiration pneumonia in elderly patients. Intern Med 2009;48:129-35. CrossRef

9. Fidan A, Cömert SŞ, Tokmak M, Saraç G, Salepçi B, Kıral N. Retrospective Analysıs Of Aspiration Pneumonia Cases. Kartal Eğitim ve Araştırma Hastanesi Tıp Dergisi 2008;19:113-6.

10. Feinberg MJ, Ekberg O, Segall L, Tully J. Deglutition in elderly patients with dementia: findings of videofluorographic evaluation and impact on staging and management. Radiology 1992;183:811-4. CrossRef

11. Metan G, Bozkurt İ, Yildız O, Alp E, Aygen B, Sümerkan B. Do We Need Blood Cultures for The Management of Aspiration Pneumonia? Erciyes Tip Dergisi 2010;32:241-6.

12. van der Maarel-Wierink CD, Vanobbergen JN, Bronkhorst EM, Schols JM, de Baat C. Oral health care and aspiration pneumonia in frail older people: a systematic literature review. Gerodontology 2013;30:3-9. CrossRef

13. Cogen R, Weinryb J. Aspiration pneumonia in nursing home patients fed via gastrostomy tubes. Am J Gastroenterol 1989;84:1509-12. 
14. Nakajoh K, Nakagawa T, Sekizawa K, Matsui T, Arai H, Sasaki H. Relation between incidence of pneumonia and protective reflexes in post-stroke patients with oral or tube feeding. J Intern Med 2000;247:39-42. CrossRef

15. Pugliese G, Lichtenberg DA. Nosocomial bacterial pneumonia: an overview. Am J Infect Control 1987;15:249-65. CrossRef

16. Marrie TJ, Durant H, Kwan C. Nursing home-acquired pneumonia. A case-control study. J Am Geriatr Soc 1986;34:697702. CrossRef

17. Bosch X, Formiga F, Cuerpo S, Torres B, Rosón B, López-Soto A. Aspiration pneumonia in old patients with dementia. Prognostic factors of mortality. Eur J Intern Med 2012;23:720-6.

18. Dines DE, Titus JL, Sessler AD. Aspiration pneumonitis. Mayo Clin Proc 1970;45:347-60.

19. Gibson PH, Cuthbertson BH, Croal BL, Rae D, El-Shafei H, Gibson G, et al. Usefulness of neutrophil/lymphocyte ratio as predictor of new-onset atrial fibrillation after coronary artery bypass grafting. Am J Cardiol 2010;105:186-91. CrossRef

20. Duffy BK, Gurm HS, Rajagopal V, Gupta R, Ellis SG, Bhatt
DL. Usefulness of an elevated neutrophil to lymphocyte ratio in predicting long-term mortality after percutaneous coronary intervention. Am J Cardiol 2006;97:993-6. CrossRef

21. Sarraf KM, Belcher E, Raevsky E, Nicholson AG, Goldstraw P, Lim E. Neutrophil/lymphocyte ratio and its association with survival after complete resection in non-small cell lung cancer. J Thorac Cardiovasc Surg 2009;137:425-8. CrossRef

22. Uthamalingam S, Patvardhan EA, Subramanian S, Ahmed W, Martin W, Daley M, et al. Utility of the neutrophil to lymphocyte ratio in predicting long-term outcomes in acute decompensated heart failure. Am J Cardiol 2011;107:433-8. CrossRef

23. Niskanen LK, Laaksonen DE, Nyyssönen K, Alfthan G, Lakka HM, Lakka TA, et al. Uric acid level as a risk factor for cardiovascular and all-cause mortality in middle-aged men: a prospective cohort study. Arch Intern Med 2004;164:1546-51. CrossRef

24. Tomita M, Mizuno S, Yamanaka H, Hosoda Y, Sakuma K, Matuoka Y, et al. Does hyperuricemia affect mortality? A prospective cohort study of Japanese male workers. J Epidemiol 2000;10:403-9. CrossRef 